\title{
Metrics of Antifungal Effects of Ciprofloxacin on Aspergillus fumigatus Planktonic Growth and Biofilm Metabolism; Effects of Iron and Siderophores
}

\author{
Gabriele Sass ${ }^{1, *}$, Lynn Scherpe ${ }^{1,2,+} \mathbb{D}$, Marife Martinez ${ }^{1}$, Julianne J. Marsh ${ }^{1, \ddagger}$ and David A. Stevens ${ }^{1,3}$ \\ 1 California Institute for Medical Research, San Jose, CA 95128, USA; lynnscherpe@gmail.com (L.S.); \\ mmartinez@cimr.org (M.M.); juliannejmarsh@gmail.com (J.J.M.); stevens@stanford.edu (D.A.S.) \\ 2 Faculty of Science and Engineering, Maastricht University, 6229 EN Maastricht, The Netherlands \\ 3 Division of Infectious Diseases and Geographic Medicine, Department of Medicine, Stanford University \\ School of Medicine, Stanford, CA 94305, USA \\ * Correspondence: gabriele.sass@cimr.org; Tel.: +1-408-998-4557 \\ + Current address: Department of Biology, Swiss Federal Institute of Technology, 8092 Zurich, Switzerland. \\ $\ddagger$ Current address: College of Arts and Sciences, University of Colorado, Boulder, CO 80309, USA.
}

check for updates

Citation: Sass, G.; Scherpe, L.; Martinez, M.; Marsh, J.J.; Stevens, D.A. Metrics of Antifungal Effects of Ciprofloxacin on Aspergillus fumigatus Planktonic Growth and Biofilm Metabolism; Effects of Iron and Siderophores. J. Fungi 2022, 8, 240. https://doi.org/10.3390/jof8030240 Academic Editors: Patrick Schwarz, Eric Dannaoui and Ronen Ben-Ami

Received: 10 December 2021

Accepted: 24 February 2022

Published: 28 February 2022

Publisher's Note: MDPI stays neutral with regard to jurisdictional claims in published maps and institutional affiliations.

Copyright: () 2022 by the authors Licensee MDPI, Basel, Switzerland. This article is an open access article distributed under the terms and conditions of the Creative Commons Attribution (CC BY) license (https:// creativecommons.org/licenses/by/ $4.0 /)$.

\begin{abstract}
Pseudomonas aeruginosa and Aspergillus fumigatus frequently coexist in the airways of immunocompromised patients or individuals with cystic fibrosis. Ciprofloxacin (CIP) is a synthetic quinolone antibiotic commonly used to treat bacterial infections, such as those produced by Pseudomonas aeruginosa. CIP binds iron, and it is unclear what effect this complex would have on the mycobiome. The effects of CIP on Aspergillus were dependent on the iron levels present, and on the presence of Aspergillus siderophores. We found that CIP alone stimulated wildtype planktonic growth, but not biofilm metabolism. At high concentrations, CIP antagonized a profungal effect of iron on wildtype Aspergillus metabolism, presumably owing to iron chelation. CIP interfered with the metabolism and growth of an Aspergillus siderophore mutant, with the effect on metabolism being antagonized by iron. CIP acted synergistically with iron on the growth of the mutant, and, to a lesser extent, the wildtype. In summary, CIP can increase fungal growth or affect fungal metabolism, depending on the local iron concentration and available siderophores. Therefore, high local CIP concentrations during treatment of Pseudomonas-Aspergillus co-infections may increase the fungal burden.
\end{abstract}

Keywords: Aspergillus; Pseudomonas; co-infection; antifungal therapy; ciprofloxacin; cystic fibrosis; iron; biofilm

\section{Introduction}

A. fumigatus and P. aeruginosa share the same polymicrobial niches, e.g., in the lungs of immunocompromised patients and people with cystic fibrosis (CF), aggravating infections [1-4]. Interactions of $A$. fumigatus and $P$. aeruginosa have been the topic of extensive research [5-10]. However, limited studies have focused on how drugs prescribed for one of these pathogens can affect the other pathogens present in the same microenvironment.

Both A. fumigatus and P. aeruginosa require and compete for iron for their growth, metabolism, and virulence, and produce siderophores for its uptake [10-12]. In people with $\mathrm{CF}$, different areas of the lungs have different concentrations of iron; in mucoid plugs, for instance, iron levels are low, while in other areas, e.g., caused by hemorrhage, an increased iron content is present $[13,14]$. The iron content in the microenvironment plays an important role in A. fumigatus and P. aeruginosa interactions, but also in their response to antibiotics and antifungals [14].

Quinolones are broad-spectrum antibiotics that act against both Gram-positive and Gram-negative bacteria [15]. Most studies previously conducted on ciprofloxacin (CIP) 
focused solely on its ability to eradicate $P$. aeruginosa, and ignored the potential effects it may have on other pathogens, as well as the effect of essential minerals, such as iron, coexisting in the niche [16,17]. The effects of CIP, especially in combination with iron, on the growth and metabolism of $A$. fumigatus have not been studied in detail.

In addition, it has been shown that Pseudomonas is able to produce a variety of quinolone compounds that have antifungal activities, such as the Pseudomonas quinolone signal [PQS] [8,10]. These molecules act as quorum-sensing signal molecules; they control the expression of virulence factors, upregulate Pseudomonas genes, are responsible for siderophore production, and, most relevantly, they act as iron chelators [18]. Their high affinity for iron allows them to bind and transport it to the bacterial cell membrane, thereby reducing the availability of free iron in the environment. Therefore, under iron-limiting conditions, PQS inhibits the metabolism of forming and preformed A. fumigatus biofilms, as well as planktonic growth $[8,10]$. Under non-limiting iron conditions, however, the growth and biofilm formation of $A$. fumigatus was enhanced, a feature dependent on the presence of Aspergillus siderophores, suggesting that interactions between PQS and siderophores enhance iron uptake by the fungus $[8,10]$.

Here, we investigated the effects of CIP on the growth and metabolism of A. fumigatus. CIP is a fluoroquinolone antibiotic prescribed to treat a large array of bacterial infections, including those produced by P. aeruginosa [19].

\section{Materials and Methods}

Materials: Ciprofloxacin (CIP, molecular mass: $331.346 \mathrm{~g} / \mathrm{mol})$, ferric iron $\left(\mathrm{FeCl}_{3}\right)$, 2,3-bis[2-methoxy-4-nitro-5-sulfophenyl]-2H-tetrazolium-5-carboxanilide inner salt (XTT), menadione, and RPMI 1640 medium were purchased from Sigma-Aldrich (St. Louis, MO, USA). The iron content in RPMI 1640 medium was below the detection limit $(<1 \mu \mathrm{M}$, measured by inductively coupled plasma optical emission spectroscopy by Paolo Visca, Rome, Italy, personal communication).

Strains and isolates: The fungal strains used in this study are shown in Table 1. The use of all microbes in our laboratory is approved by the CIMR Biological Use Committee (approval no. 001-03Yr.16).

Table 1. A. fumigatus strains and isolates used in this study.

\begin{tabular}{lcccc}
\hline Organism & Isolate & Description & ATCC & Ref. \\
\hline A. fumigatus & AF13073 & Parental strain of AF13073/sidA- & 13073 & \\
\hline A. fumigatus & AF13073/sidA- & L-ornithine- $N$ 5-mono-oxygenase deficient $A f$ mutant strain & & [20] \\
\hline A. fumigatus & 10AF & Virulent patient isolate & 90240 & {$[21,22]$} \\
\hline
\end{tabular}

Aspergillus forming biofilm metabolism assay: Test substances were combined in equal parts by volume ( $25 \mu \mathrm{L}$ each) in sterile flat-bottom 96-well culture plates to prepare the final concentrations indicated in the figures and figure legends. RPMI 1640 medium served as the negative control. A. fumigatus conidia $\left(10^{5} / \mathrm{mL}\right.$ final concentration for the wildtype, or $2 \times 10^{5} / \mathrm{mL}$ final concentration for the siderophore-deficient mutant) were distributed into each well at $50 \mu \mathrm{L} /$ well. The mutant was used at a higher conidia concentration to assure hyphal growth similar to the wildtype, as measured in RPMI controls, without the addition of drugs. The equal growth of controls at the end of the comparative experiments was verified microscopically, as well as by XTT measurements. As an example, the XTT measurements at $490 \mathrm{~nm}$ for the control (no iron, no CIP) wells on three 96-well plates per fungus were as follows: AF13073 wildtype: 0.203, 0.215, and 0.241; SidA mutant: 0.192, 0.252 , and 0.243 . Each plate was normalized to its individual control, and the mean for all 3 plates per fungus was regarded as the result for one experiment. Final volumes in the wells during the assays were $100 \mu \mathrm{L}$. The assay plates were incubated at $37^{\circ} \mathrm{C}$ overnight. All biofilm assays were evaluated by an XTT metabolic assay, as detailed previously $[5,23]$. Briefly, $150 \mu \mathrm{L}$ of an XTT/menadione mixture $(150 \mu \mathrm{g} / \mathrm{mL}$ XTT, $30 \mu \mathrm{M}$ menadione) was 
added to each test well and incubated at $37^{\circ} \mathrm{C}$ for about one hour. Supernatants from each well were transferred to a fresh 96-well plate $(100 \mu \mathrm{L})$ and assayed using a plate reader (Vmax, Molecular Devices, San Jose, CA, USA) at $490 \mathrm{~nm}$. All results were calculated as percent of the RPMI control present in each individual experiment, set at $100 \%$. We also performed a preliminary experiment, where we incubated CIP with the XTT reaction liquid to try to determine whether CIP affects the XTT reaction. We did not observe differences in the measurements at $490 \mathrm{~nm}$ between the control wells, containing only the XTT reaction liquid, and the wells containing different concentrations of CIP.

Assay for visual measurement of Aspergillus planktonic growth: The test substances were combined in equal parts by volume ( $50 \mu \mathrm{L}$ each), in sterile $4 \mathrm{~mL}$ culture tubes, to prepare the final concentrations indicated in the figures and figure legends. The RPMI 1640 medium served as the negative control. A total of $900 \mu \mathrm{L}$ of A. fumigatus inoculum, prepared according to the CLSI guidelines for Aspergillus broth macro-dilution, was added to the tubes. The tubes were incubated for $48 \mathrm{~h}$ at $35{ }^{\circ} \mathrm{C}$. The amount of A. fumigatus planktonic growth observed in each tube was examined visually, and reviewed by $3-5$ of the authors. Following the CLSI protocol, a 4+ reading was assigned to the control tube (RPMI with A. fumigatus, no test substance) at the time of reading. At this time, all other tubes were compared to the control. Readings from 0 to $3+$ were assigned to all tubes that appeared to have less A. fumigatus growth than the control, while a reading of 0 indicated no visible $A$. fumigatus growth. For research purposes, $5+$ or $6+$ readings were assigned to all tubes containing increasing levels of $A$. fumigatus growth compared to the control.

In many experiments, we compared spectrophotometric readings of planktonic growth with visual readings. We found that spectrophotometric readings of growth were more difficult to analyze and were less sensitive than visual readings for the filamentous fungus. The fungus tends to stick to the sides of the tubes, causing poor spectrophotometric reproducibility. Although spectrophotometric readings grossly concurred with visual readings, for the reasons stated, we utilized visual assessments of fungal growth.

Optical evaluation of fungal growth on filter paper: Following visual measurement of A. fumigatus planktonic growth in $1 \mathrm{~mL}$ of volume, $1 \mathrm{~mL}$ of XTT solution $(150 \mu \mathrm{g} / \mathrm{mL}$ $\mathrm{XTT}, 30 \mu \mathrm{M}$ menadione) was added to each tube, and the tubes were incubated at $35^{\circ} \mathrm{C}$ for approximately one hour. The stained contents of the tubes were transferred onto filter paper. The filter papers were air-dried, and a photograph was taken.

Reagent interaction studies: Two-dimensional reagent interaction ("checkerboard") studies were performed, as previously detailed [24], and the concentrations studied are delineated in the Results Section 3.

Statistical analysis: Each assay was performed several times, as indicated in the figure legends. The results were analyzed by Student's $t$-test when two groups were compared, and by 1-way ANOVA, combined with a Tukey's post-test, for multiple comparisons. All statistical data in this study are expressed as mean \pm SD.

\section{Results}

\subsection{CIP Reduces A. fumigatus Biofilm Metabolism in the Absence of Siderophores}

The natural fluoroquinolone PQS has been shown to interfere with the metabolism and growth of A. fumigatus under iron-limiting conditions [8,10]. Using the synthetic fluoroquinolone CIP under the same iron-limiting conditions, created by the use of the RPMI 1640 medium, in which iron is not detectable $(<1 \mu \mathrm{M})$, CIP did not affect the metabolism of the A. fumigatus wildtype (AF13073) biofilm at concentrations up to $1 \mathrm{mg} / \mathrm{mL}$ (Figure 1A). In contrast, the metabolism of the siderophore-deficient mutant of AF13073 (AF13073/sidA-) was reduced significantly at CIP concentrations of $15.6 \mu \mathrm{g} / \mathrm{mL}$ or higher (up to $1 \mathrm{mg} / \mathrm{mL}$ ) (Figure 1B). 

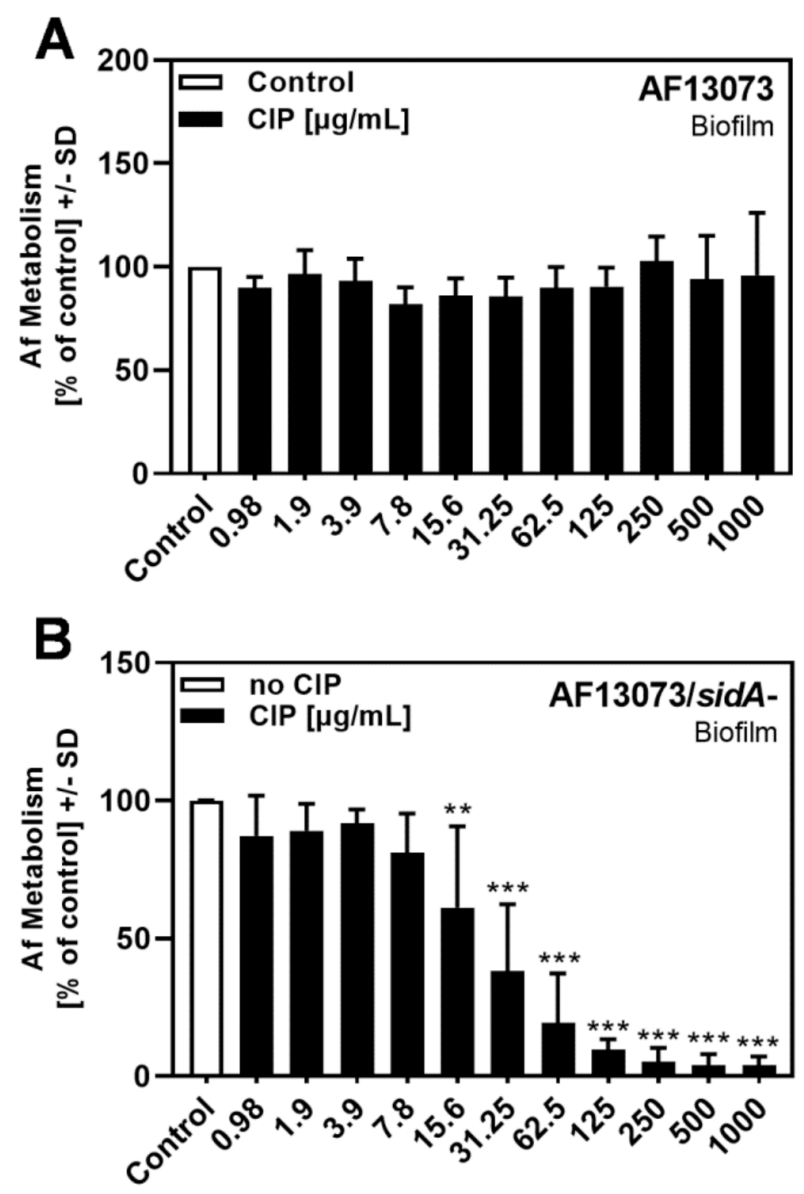

Figure 1. CIP reduces $A$. fumigatus biofilm metabolism in the absence of siderophores. CIP (final concentrations $0.98-1000 \mu \mathrm{g} / \mathrm{mL}$ in RPMI 1640 medium, x-axis) was combined with (A) AF13073 conidia (10 5 conidia/mL in RPMI 1640 medium) or (B) AF13073/sidA- conidia $\left(2 \times 10^{5}\right.$ conidia/mL in RPMI 1640 medium). As the siderophore-deficient mutant has slower growth, using double the amount of conidia assured similar growth to the wildtype in the untreated controls for both fungi. Assay plates were incubated at $37^{\circ} \mathrm{C}$ overnight. Fungal metabolism was measured by an XTT assay. The metabolism in the presence of RPMI alone was regarded as $100 \%$, and was compared to each supernatant dilution. Statistical analysis, 1-way ANOVA: two or three asterisks $=p \leq 0.01$ or $p \leq 0.001$, respectively. Comparison: RPMI (white bar) vs. all other bars (black bars). A: $n=6-7$; B: $n=4-5$.

\subsection{CIP Induces A. fumigatus Planktonic Wildtype Growth, but Reduces Planktonic Growth of a} Siderophore-Deficient Mutant

In contrast to the findings for biofilm metabolism (Figure 1), high concentrations of CIP $(250 \mu \mathrm{g} / \mathrm{mL}$ up to $1 \mathrm{mg} / \mathrm{mL}$ ) showed profungal effects on AF13073 wildtype planktonic growth (Figure 2A). The same concentrations had antifungal effects on the planktonic growth of the siderophore-deficient fungus (Figure 2B). 


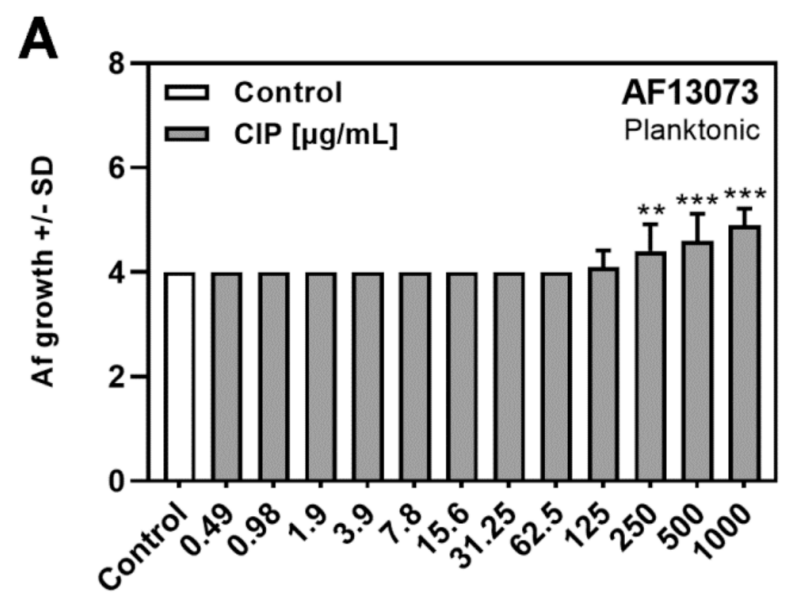

B

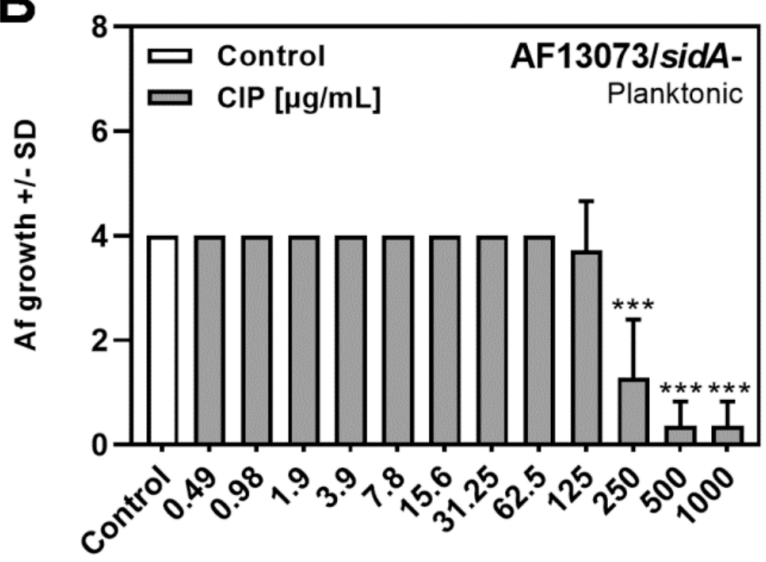

Figure 2. CIP induces $A$. fumigatus planktonic wildtype growth, but reduces planktonic growth of the siderophore-deficient mutant. CIP (final concentrations $0.49-1000 \mu \mathrm{g} / \mathrm{mL}$ in RPMI 1640 medium, x-axis) was combined with (A) AF13073 or (B) AF13073/sidA-conidia according to the CSLI guidelines for macro-dilution. The tubes were incubated at $37^{\circ} \mathrm{C}$ for $48 \mathrm{~h}$. Fungal growth was measured visually, and rated as described in the Material and Methods section, with growth in control tubes assigned a ' 4 '. The tubes with less growth were rated a number between 0 and 3 , and for tubes with more growth than the control, a number 5 or 6, depending on relative amount of growth. Statistical analysis, 1-way ANOVA: two or three asterisks $=p \leq 0.01$ or $p \leq 0.001$, respectively. Comparison: RPMI (white bar) vs. all other bars (grey bars). A: $n=8-10 ; \mathrm{B}: n=7$.

The profungal effects of CIP on planktonic growth were also visualized after $48 \mathrm{~h}$ of growth, by staining and plating the wildtype fungus on filter paper. The AF13073 wildtype showed visually enhanced growth $\geq 250 \mu \mathrm{g} / \mathrm{mL}$ (Figure $3 \mathrm{~A}$ ), and the 10AF wildtype showed visually enhanced growth $\geq 62.5 \mu \mathrm{g} / \mathrm{mL}$ (Figure $3 \mathrm{~B}$ ). Compared to the control $=100 \%$ (RPMI, no drug), CIP (62.5 ug/mL) increased the biomass by $26 \%$ (AF13073) and $78 \%$ (10AF). No further increase in the biomass was observed when $\geq 250 \mathrm{ug} / \mathrm{mL}$ CIP was used (maximum increase in the biomass over control was as follows: AF13073:186\%, 10AF: $105 \%)$. 


\section{A: AF13073: CIP $[\mu \mathrm{g} / \mathrm{mL}]$}

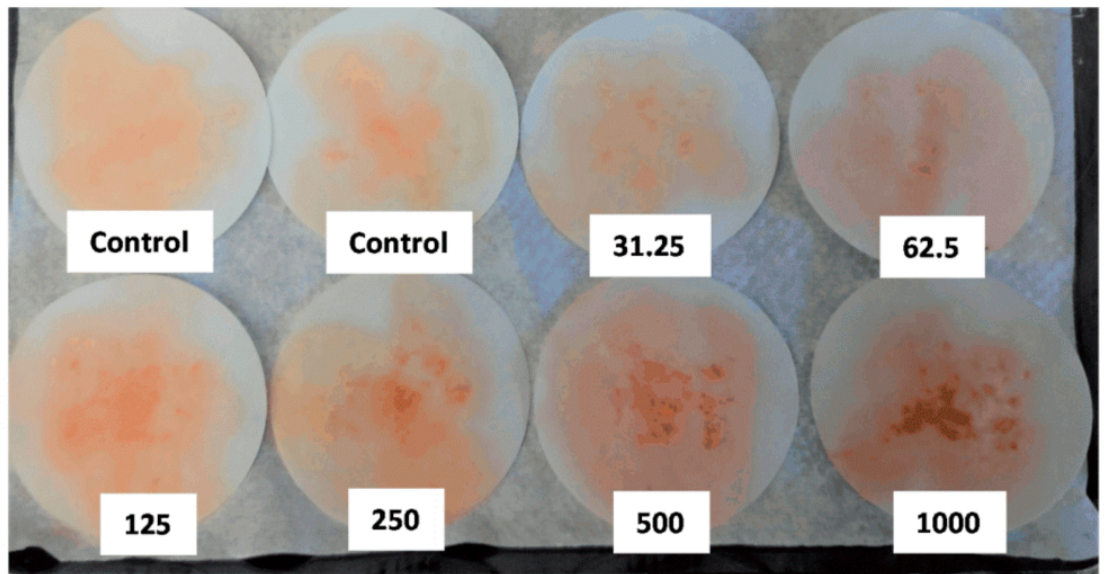

\section{B: 10AF: CIP $[\mu \mathrm{g} / \mathrm{mL}]$}

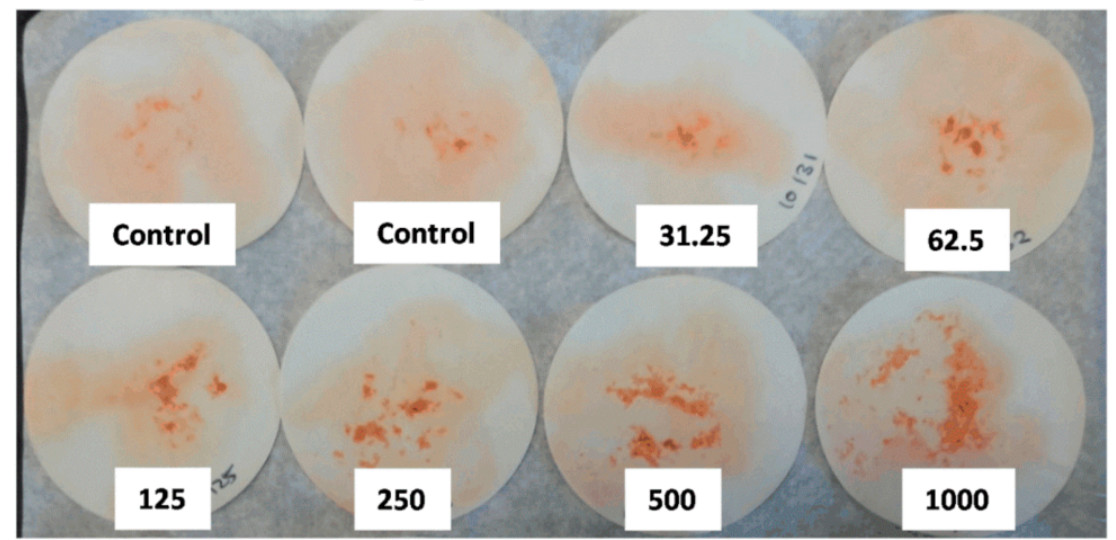

Figure 3. CIP induces planktonic growth of A. fumigatus wildtype strains AF13073 (A) and 10AF (B). After $48 \mathrm{~h}$ of planktonic growth in the presence of CIP (final concentrations 31.25-1000 $\mu \mathrm{g} / \mathrm{mL}$ in RPMI 1640 medium), tubes were diluted 1:2 with XTT solution, incubated at $37^{\circ} \mathrm{C}$ for $30 \mathrm{~min}$, and the complete content of each tube was spread on filter paper.

\subsection{Iron Induces the Metabolism and Growth of A. fumigatus}

Iron is a crucial factor for the growth and metabolism of Aspergillus [9,10,12]. Our results confirmed this finding, showing significantly increased AF13073 wildtype metabolism (Figure $4 \mathrm{~A}$ ) and growth (Figure $4 \mathrm{~B}$ ) $\geq 0.78$ and $6.25 \mu \mathrm{M}$, respectively. The siderophoredeficient Aspergillus mutant was more responsive to iron than its wildtype, showing significantly increased metabolism $\geq 0.19 \mu \mathrm{M}$ (Figure 4C), which was the lowest concentration tested, and significantly increased growth from $0.39 \mu \mathrm{M}$ (Figure 4D). 
A
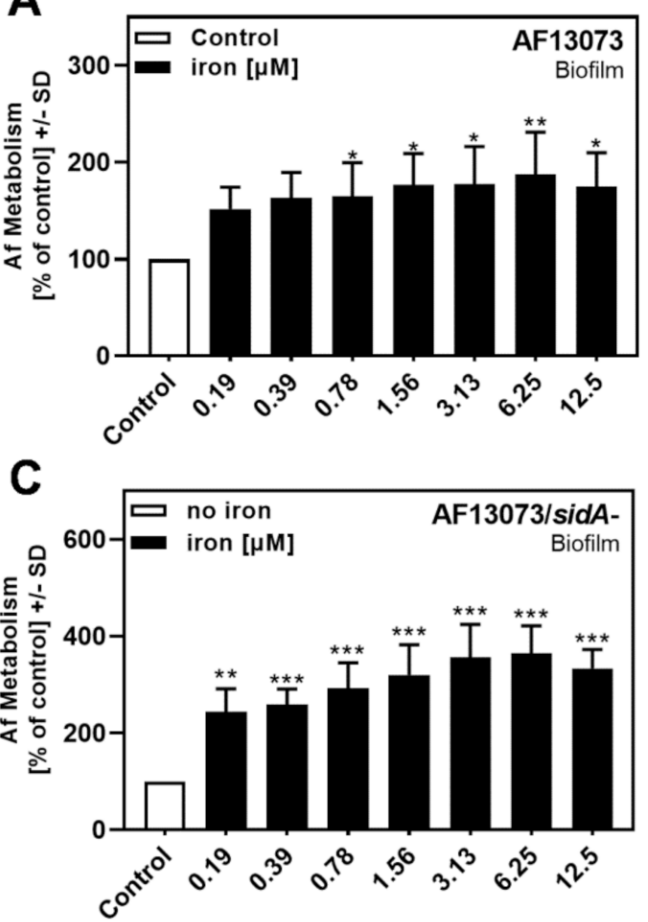

B
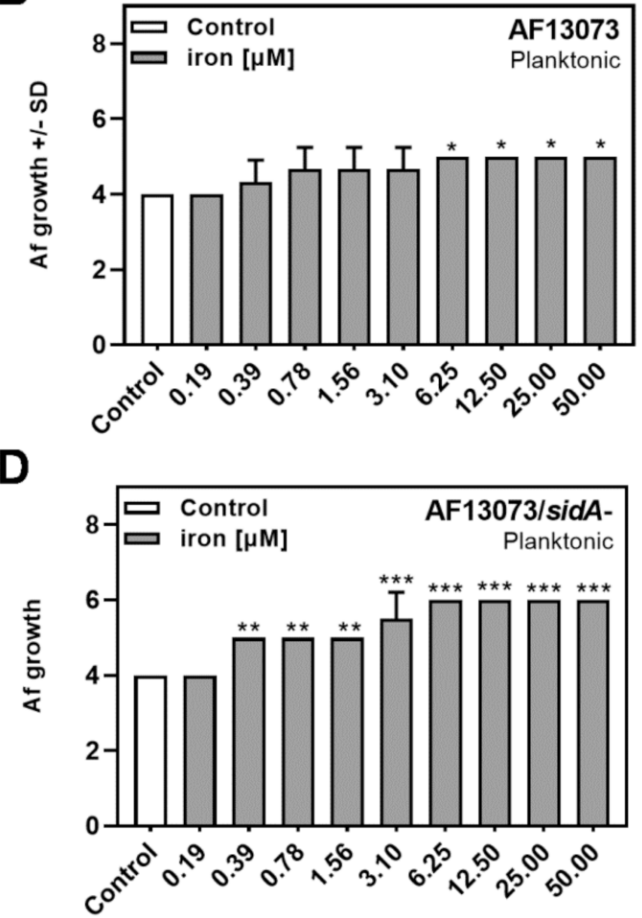

Figure 4. Iron induces the metabolism and growth of $A$. fumigatus. $\mathrm{FeCl}_{3}$ (iron; final concentrations 0.19-12.5 $\mu \mathrm{M}$ in RPMI 1640 medium, $\mathrm{x}$-axis) was combined with (A,B) AF13073 conidia or (C,D) AF13073/sidA- conidia. (A,C) For the measurement of biofilm metabolism, plates were incubated at $37^{\circ} \mathrm{C}$ overnight. Fungal metabolism was measured by an XTT assay. (B,D) The tubes for planktonic fungal growth were incubated at $37^{\circ} \mathrm{C}$ for $48 \mathrm{~h}$. Fungal growth was measured visually, and rated as described in the Material and Methods section. Biofilm metabolism or planktonic growth in the presence of RPMI alone was compared to each iron concentration. Statistical analysis, 1-way ANOVA: one, two or three asterisks $=p \leq 0.05, p \leq 0.01$ or $p \leq 0.001$, respectively.

\subsection{Iron and CIP Interact and Affect A. fumigatus Biofilm Metabolism}

When CIP and iron were combined, CIP concentrations as low as $0.98 \mu \mathrm{g} / \mathrm{mL}$ interfered with the profungal effects of iron on the AF13073 wildtype, from $0.19 \mu \mathrm{M}$ iron to about $3 \mu \mathrm{M}$ (Figure 5A). At high concentrations of CIP, 500 and $1000 \mu \mathrm{g} / \mathrm{mL}$, the profungal effects of iron were almost abolished (Figure 5A). On the siderophore-deficient fungus, the iron antagonized the antifungal effects of CIP in a dose-dependent manner (Figure 5B). High concentrations of CIP (500 and $1000 \mu \mathrm{g} / \mathrm{mL}$ ) reduced the profungal effects of iron, even if the iron was used at the highest concentration tested here, $12.5 \mu \mathrm{M}$ (Figure 5B).

\subsection{Iron Does Not Further Increase Profungal Effects of CIP on A. fumigatus Planktonic Growth}

High concentrations of CIP alone (Figure $2 \mathrm{~A}$ ) or iron alone $\geq 6.25 \mu \mathrm{M}$ (Figure $4 \mathrm{~B}$ ) had profungal effects on the AF13073 wildtype. When CIP and iron were combined, there was no further increase in growth, except for the combination of $0.19 \mu \mathrm{M}$ iron with CIP at $31.3-125 \mu \mathrm{g} / \mathrm{mL}$ (Figure 6A). On the siderophore-deficient Aspergillus, the combination of iron at $0.19 \mu \mathrm{M}$ with CIP at 7.8 to $125 \mu \mathrm{g} / \mathrm{mL}$ resulted in increased growth, compared to each factor alone (Figure 6B). CIP interfered with the profungal effects of the higher iron concentrations (Figure 6B). The antifungal effects of CIP (250 $\mathrm{gg} / \mathrm{mL}$ or higher) were antagonized by iron (Figure 6B). 


\section{A: AF13073}

\begin{tabular}{|c|c|c|c|c|c|c|c|c|c|c|c|c|c|}
\hline Fe & & & & & & & & & & & & & \\
\hline $\mathbf{1 2 . 5}$ & 159 & 166 & 177 & 158 & 152 & 167 & 155 & 156 & 174 & 188 & 127 & 92 & \\
\hline $\mathbf{6 . 2 5}$ & 166 & 157 & 148 & 130 & 154 & 156 & 111 & 130 & 171 & 156 & 106 & 79 & \\
\hline $\mathbf{3 . 1 3}$ & 158 & 147 & 125 & 132 & 138 & 144 & 116 & 133 & 145 & 165 & 124 & 80 & \\
\hline $\mathbf{1 . 5 6}$ & 163 & 143 & 147 & 139 & 113 & 118 & 142 & 132 & 146 & 148 & 106 & 50 & \\
\hline $\mathbf{0 . 7 8}$ & 155 & 140 & 120 & 122 & 128 & 118 & 123 & 119 & 129 & 150 & 96 & 46 & \\
\hline $\mathbf{0 . 3 9}$ & 151 & 124 & 126 & 107 & 108 & 116 & 115 & 130 & 129 & 135 & 96 & 48 & \\
\hline $\mathbf{0 . 1 9}$ & 141 & 144 & 125 & 130 & 131 & 149 & 127 & 125 & 132 & 133 & 104 & 60 & \\
\hline $\mathbf{C}$ & 100 & $\mathbf{9 1}$ & 99 & 93 & 85 & 92 & 92 & 93 & 89 & 95 & 73 & 73 & \\
\hline & $\mathbf{C}$ & $\mathbf{0 . 9 8}$ & $\mathbf{1 . 9}$ & $\mathbf{3 . 9}$ & $\mathbf{7 . 8}$ & $\mathbf{1 5 . 6}$ & $\mathbf{3 1 . 3}$ & $\mathbf{6 2 . 5}$ & $\mathbf{1 2 5}$ & $\mathbf{2 5 0}$ & $\mathbf{5 0 0}$ & $\mathbf{1 0 0 0}$ & $\mathbf{C I P}$ \\
\hline
\end{tabular}

\section{B: AF13073/sidA-}

\begin{tabular}{|c|c|c|c|c|c|c|c|c|c|c|c|c|c|}
\hline $\mathrm{Fe}$ & & & & & & & & & & & & & \\
\hline 12.5 & 326 & 377 & 404 & 400 & 402 & 401 & 404 & 384 & 363 & 330 & 286 & 216 & \\
\hline 6.25 & 377 & 361 & 359 & 374 & 371 & 370 & 346 & 342 & 332 & 325 & 295 & 224 & \\
\hline 3.13 & 372 & 331 & 346 & 327 & 363 & 358 & 344 & 343 & 336 & 286 & 268 & 202 & \\
\hline 1.56 & 318 & 312 & 328 & 325 & 317 & 324 & 306 & 316 & 301 & 273 & 242 & 220 & \\
\hline 0.78 & 298 & 288 & 295 & 284 & 293 & 301 & 270 & 287 & 251 & 219 & 131 & 151 & \\
\hline 0.39 & 249 & 244 & 236 & 208 & 235 & 256 & 260 & 256 & 189 & 64 & 55 & 144 & \\
\hline 0.19 & 226 & 190 & 192 & 184 & 183 & 187 & 212 & 184 & 129 & 20 & 22 & 46 & \\
\hline C & 100 & 99 & 94 & 91 & 93 & 83 & 63 & 37 & 12 & 5 & 5 & 4 & \\
\hline & c & 0.98 & 1.9 & 3.9 & 7.8 & 15.6 & 1.3 & 62.5 & 125 & 250 & 500 & 1000 & CIP \\
\hline
\end{tabular}

\begin{tabular}{|c|c|}
\hline & 0 to 5 \\
\hline & 6 to 25 \\
\hline $26-50$ \\
\hline 51 to 100 \\
\hline 101 to 150 \\
\hline $151-200$ \\
\hline $201-300$ \\
\hline$>300$ \\
\hline
\end{tabular}

Figure 5. Iron and CIP interact and affect A. fumigatus biofilm metabolism. CIP (final concentration $0.98-1000 \mu \mathrm{g} / \mathrm{mL}$ in RPMI 1640 medium) was combined with $\mathrm{FeCl}_{3}$ (iron; final concentration $0.19-12.5 \mu \mathrm{M}$ in RPMI 1640 medium) using (A) AF13073 conidia (10 5 conidia/mL in RPMI 1640 medium) or (B) AF13073/sidA-conidia $\left(2 \times 10^{5}\right.$ conidia/mL in RPMI 1640 medium). As the siderophore-deficient mutant has slower growth, using double the amount of conidia assured similar growth to the wildtype in the untreated controls for both fungi. The assay plates were incubated at $37^{\circ} \mathrm{C}$ overnight. Fungal metabolism was measured by an XTT assay. Metabolism in the presence of RPMI alone was regarded as $100 \%$, and compared to each supernatant dilution. The color chart visualizes groups of iron/CIP combinations with similar growth. A: $n=2$; B: $n=2$. 


\section{A: AF13073}

\begin{tabular}{|c|c|c|c|c|c|c|c|c|c|c|c|c|c|c|}
\hline $\mathrm{Fe}$ & & & & & & & & & & & & & & \\
\hline $\mathbf{5 0}$ & 5 & & & & & & & & & & & & & \\
\hline $\mathbf{2 5}$ & 5 & 5 & 5 & 5 & 5 & 5 & 5 & 5 & 5 & 5 & 5 & 5 & & \\
\hline $\mathbf{1 2 . 5}$ & 5 & 5 & 5 & 5 & 5 & 5 & 5 & 5 & 5 & 5 & 5 & 5 & & \\
\hline $\mathbf{6 . 2 5}$ & 5 & 5 & 5 & 5 & 5 & 5 & 5 & 5 & 5 & 5 & 5 & 5 & & \\
\hline 3.1 & 5 & 5 & 5 & 5 & 5 & 5 & 5 & 5 & 5 & 5 & 5 & 5 & & \\
\hline 1.56 & 5 & 5 & 5 & 5 & 5 & 5 & 5 & 5 & 5 & 5 & 5 & 5 & & \\
\hline 0.78 & 5 & 5 & 5 & 5 & 5 & 5 & 5 & 5 & 5 & 5 & 5 & 5 & & \\
\hline 0.39 & 5 & 4 & 5 & 5 & 5 & 5 & 5 & 5 & 5 & 5 & 5 & 5 & & \\
\hline 0.19 & 4 & 4 & 4 & 4 & 4 & 4 & 4 & 5 & 5 & 5 & 5 & 5 & & \\
\hline $\mathrm{C}$ & 4 & 4 & 4 & 4 & 4 & 4 & 4 & 4 & 4 & 4 & 5 & 5 & 5 & \\
\hline & $\mathrm{C}$ & 0.49 & 0.98 & 1.9 & 3.9 & 7.8 & 15.6 & 31.3 & 62.5 & 125 & $\mathbf{2 5 0}$ & $\mathbf{5 0 0}$ & 1000 & $\mathrm{CIP}$ \\
\hline
\end{tabular}

\section{B: AF13073/sidA-}

\begin{tabular}{|c|c|c|c|c|c|c|c|c|c|c|c|c|c|c|}
\hline Fe & & & & & & & & & & & & & & \\
\hline $\mathbf{5 0}$ & 6 & & & & & & & & & & & & & \\
\hline $\mathbf{2 5}$ & 6 & 5 & 5 & 5 & 5 & 5 & 5 & 5 & 5 & 5 & 4 & 4 & & \\
\hline $\mathbf{1 2 . 5}$ & 6 & 5 & 5 & 5 & 5 & 5 & 5 & 5 & 5 & 5 & 4 & 4 & & \\
\hline $\mathbf{6 . 2 5}$ & 6 & 5 & 5 & 5 & 5 & 5 & 5 & 5 & 5 & 5 & 4 & 4 & & \\
\hline 3.1 & 6 & 5 & 5 & 5 & 5 & 5 & 5 & 5 & 5 & 5 & 4 & 4 & & \\
\hline 1.56 & 5 & 5 & 5 & 5 & 5 & 5 & 5 & 5 & 5 & 5 & 5 & 4 & & \\
\hline $\mathbf{0 . 7 8}$ & 5 & 5 & 5 & 5 & 5 & 5 & 5 & 5 & 5 & 5 & 5 & 3 & & \\
\hline $\mathbf{0 . 3 9}$ & 5 & 5 & 5 & 5 & 5 & 5 & 5 & 5 & 5 & 5 & 4 & 1 & & \\
\hline $\mathbf{0 . 1 9}$ & 4 & 4 & 4 & 4 & 4 & 5 & 5 & 5 & 5 & 5 & 4 & 1 & & \\
\hline $\mathrm{C}$ & 4 & 4 & 4 & 4 & 4 & 4 & 4 & 4 & 4 & 4 & 3 & 1 & 1 & \\
\hline & $\mathrm{C}$ & 0.49 & 0.98 & 1.9 & 3.9 & $\mathbf{7 . 8}$ & $\mathbf{1 5 . 6}$ & $\mathbf{3 1 . 3}$ & $\mathbf{6 2 . 5}$ & $\mathbf{1 2 5}$ & $\mathbf{2 5 0}$ & $\mathbf{5 0 0}$ & 1000 & $\mathrm{CIP}$ \\
\hline
\end{tabular}

\begin{tabular}{|c|c|c|}
\hline & 0 & 0 \\
\hline & tr & 0.5 \\
\hline & $1+$ & 1 \\
\hline & $2+$ & 2 \\
\hline & $3+$ & 3 \\
\hline & $4+$ & 4 \\
\hline & $4++$ & 5 \\
\hline & $4+++$ & 6 \\
\hline
\end{tabular}

Figure 6. Iron does not further increase the profungal effects of CIP on the planktonic growth of A. fumigatus. CIP (final concentrations $0.49-1000 \mu \mathrm{g} / \mathrm{mL}$ in RPMI 1640 medium) was combined with $\mathrm{FeCl}_{3}$ (iron; final concentration $0.19-12.5 \mu \mathrm{M}$ in RPMI 1640 medium) using (A) AF13073 or (B) AF13073/sidA-conidia, according to CSLI guidelines for macro-dilution. The tubes were incubated at $37^{\circ} \mathrm{C}$ for $48 \mathrm{~h}$. Fungal growth was measured visually, and rated as described in the Material and Methods section, with the growth in control tubes being assigned a ' 4 ', as per CLSI methodology. The tubes with less growth were rated a number between 0 and 3 , and for the tubes with more growth than the control, a number 5 or 6 , proportional to the amounts of growth. The color chart visualizes groups of iron/CIP combinations with the same growth. A: $n=2 ; \mathrm{B}: n=2$.

\section{Discussion}

We confirmed our prior studies findings, which showed that iron stimulates the metabolism and growth of the wildtype [8,25]. The profungal effects of CIP on the wildtype fungus were only detected at concentrations $>125 \mu \mathrm{g} / \mathrm{mL}$, and for planktonic growth, but not for biofilm metabolism. These profungal effects on planktonic growth were observed by two different methods, and on two wildtype strains, AF13073 and 10AF. It would enhance our findings if more Aspergillus strains were studied. An explanation for the discrepancy between the CIP effects on planktonic growth and biofilm metabolism might be that fungal biofilms are more drug resistant, making this feature one of the pathogen's 
most important virulence factors, interfering with eradication of the infection [26,27]. In addition, the XTT assay assessed the mitochondrial oxidative metabolism. CIP appears to have an effect on the enzymes affecting the growth of the planktonic wildtype A. fumigatus, but may have a differential effect on the dehydrogenase enzymes that are involved in mitochondrial respiration $[28,29]$. Furthermore, it is speculated that CIP dysregulates electron transfer, presenting an additional reason for the discrepancy between the XTT and growth results [30].

CIP antagonizes the profungal effect of iron on wildtype metabolism, presumably by CIP chelation of iron. CIP has a far lesser effect on the stimulation of wildtype planktonic growth by iron; some synergy was observed, suggesting that there may be some CIP assistance in delivering iron to $A$. fumigatus.

In the case of the A. fumigatus that lacks siderophores, CIP has a profound depressing effect on both the metabolism and planktonic growth, presumably by severe iron denial. These putative mechanisms of CIP action require further study.

The effects of CIP on biofilm metabolism are stronger than the effects on planktonic growth. It has been shown that Aspergillus biofilms are very sensitive to iron starvation $[7,10]$. Supplying external iron alone has a much greater stimulatory effect on the siderophore mutant than on the wildtype, likely because the mutant can now take advantage of other possible means of acquiring iron from its environment, including diffusion and oxidation-reduction to $\mathrm{Fe}^{2+}$. Iron antagonizes the antifungal effects of $\mathrm{CIP}$ on metabolism, and this suggests that the added iron can supply some of the iron that CIP would otherwise deny. However, at high CIP concentrations, the stimulatory effect of iron on metabolism is antagonized (as was observed with the wildtype), and we hypothesize that these high concentrations can produce an iron deficit by excessive iron chelation.

The discovery of naturally occurring quinolones led to the development of synthetic quinolone drugs, such as CIP [18]. CIP, a fluoroquinolone, is a bactericide that inhibits the enzymes DNA topoisomerase and DNA gyrase, involved in bacterial DNA replication [31]. Fungi possess high levels of topoisomerase I and II [32], making them possible targets for CIP.

Quinolone drugs, other than CIP, were previously examined for their effects on A. fumigatus growth. These studies showed that quinolones can inhibit fungal growth by interacting with topoisomerase II [32,33]. One study also found that the quinoline bromoquinol exhibits broad-spectrum antifungal activity by inducing oxidative stress and apoptosis in A. fumigatus [34]. Another study that examined the effects of CIP on numerous fungi, not including A. fumigatus, found no inhibitory effects on H. capsulatum and C. posadasii growth [33], and Stergiopoulou et al. [32] discovered that CIP was even able to increase $A$. fumigatus growth, but they did not postulate a mechanism of action.

The CIP concentrations $>125 \mu \mathrm{g} / \mathrm{mL}$, triggering increased planktonic fungal growth, were well above the therapeutic serum range of up to $7.27 \mathrm{mg} / \mathrm{L}$, which can be achieved by taking CIP orally; this is the most common form of administration [35]. However, recent studies have shown that via other methods of administration, higher CIP concentrations can be deposited at the site of infection. A clinical study performed on pneumonia patients, where the infection occurs in the alveolar spaces and pulmonary interstitium, found that CIP concentrations could reach up to $34.9 \mu \mathrm{g} / \mathrm{mL}$ in alveolar macrophages, measured four hours after intravenous infusion of $400 \mathrm{mg}$ CIP [36]. Inhaling CIP deposits even higher concentrations in the airways of CF patients [37,38]. Therefore, these forms of CIP administration pose greater risks of promoting $A$. fumigatus during co-infections.

It is known that oral iron reduces quinolone bioavailability [39,40], as a result of iron binding to ciprofloxacin and complexation. Kara et al. [41] found that ciprofloxacin increases the rate of ferrous iron $\left[\mathrm{Fe}^{2+}\right]$ oxidation, and thereupon binds rapidly to the resulting ferric iron $\left[\mathrm{Fe}^{3+}\right]$ to form a CIP-Fe complex. These complexes are poorly absorbed by the body, and decrease the amount of CIP and bioavailable iron. In consequence of the reduced iron availability, one might assume that antifungal effects are taking place. However, in our study, the combination of CIP and iron increased the growth of the 
wildtype A. fumigatus modestly more than each reagent alone. In future studies, it would be interesting to investigate the effects of CIP on Aspergillus siderophore production. Iron complexation might increase siderophore production, which would allow more iron uptake by the fungus, and more growth.

Iron levels in certain areas of CF patient lungs are already elevated [42], supporting fungal growth, but the present study determined that iron concentrations as low as $0.2 \mu \mathrm{M}$, in combination with $15.6 \mu \mathrm{g} / \mathrm{mL} \mathrm{CIP}$, are sufficient to enhance the growth of the wildtype A. fumigatus. These results may suggest that CIP can act similarly to PQS, by feeding iron to A. fumigatus, via interactions with $A$. fumigatus siderophores. In previous studies, we found that PQS can boost the growth of A. fumigatus in high-iron environments, and that, for this to happen, A. fumigatus siderophores must be present [8]. The prolonged residence of microbes in chronic infections, a changing iron milieu, and the competition or cooperation with other members of the microbiome, can induce mutations that downplay the need for energy-consuming siderophore production [2].

\section{Impact}

Previous studies have focused on the effects of naturally occurring quinolones on A. fumigatus; however, such studies have paid less attention to the possible effects of clinically prescribed synthetic quinolones on this pathogen. As bacteria and fungi commonly coexist in the airways of immunocompromised patients and people with $\mathrm{CF}$, it is important that the effect of each clinically prescribed antibiotic or antifungal is tested on all microorganisms that may be present in the target niche. The present study revealed that the antibiotic ciprofloxacin can potentially stimulate A. fumigatus growth in the airways of immunocompromised patients and people with $\mathrm{CF}$, especially in areas where iron levels are high. Therefore, while eradicating the bacterial infection, CIP treatment could worsen a coexisting Aspergillus infection, and, thereby, the overall health of the patient. This research should make clinicians aware of the risks associated with prescribing CIP.

Author Contributions: Conceptualization, D.A.S.; methodology, D.A.S.; software, D.A.S.; validation, G.S. and D.A.S.; formal analysis, G.S.; investigation, G.S., L.S., M.M. and J.J.M.; resources, D.A.S.; data curation, G.S.; writing — original draft preparation, G.S. and L.S.; writing — review and editing, D.A.S., L.S., M.M. and J.J.M.; visualization, G.S.; supervision, D.A.S. and G.S.; project administration, D.A.S.; funding acquisition, D.A.S. All authors have read and agreed to the published version of the manuscript.

Funding: This research was funded by the Foundation for Research in Infectious Diseases (FRID), grant number 8201.

Institutional Review Board Statement: Not applicable.

Informed Consent Statement: Not applicable.

Data Availability Statement: Data are available from the corresponding author upon request.

Conflicts of Interest: The authors declare no conflict of interest. The funders had no role in the design of the study; in the collection, analyses, or interpretation of data; in the writing of the manuscript, or in the decision to publish the results.

\section{References}

1. King, J.; Brunel, S.F.; Warris, A. Aspergillus infections in cystic fibrosis. J. Infect. 2016, 72, S50-S55. [CrossRef] [PubMed]

2. O'Brien, S.; Fothergill, J.L. The role of multispecies social interactions in shaping Pseudomonas aeruginosa pathogenicity in the cystic fibrosis lung. FEMS Microbiol. Lett. 2017, 364, fnx128. [CrossRef] [PubMed]

3. Wambaugh, M.A.; Denham, S.T.; Brammer, B.; Stonhill, M.; Brown, J.C. Synergistic and antagonistic drug interactions in the treatment of systemic fungal infections. Elife 2020, 9, e54160. [CrossRef] [PubMed]

4. Elborn, J.S. Cystic fibrosis. Lancet 2016, 388, 2519-2531. [CrossRef]

5. Ferreira, J.A.; Penner, J.C.; Moss, R.B.; Haagensen, J.A.; Clemons, K.V.; Spormann, A.M.; Nazik, H.; Cohen, K.; Banaei, N.; Carolino, E.; et al. Inhibition of Aspergillus fumigatus and its biofilm by Pseudomonas aeruginosa is dependent on the source, phenotype and growth conditions of the bacterium. PLoS ONE 2015, 10, e0134692. [CrossRef] 
6. Schwarz, C.; Hartl, D.; Eickmeier, O.; Hector, A.; Benden, C.; Durieu, I.; Sole, A.; Gartner, S.; Milla, C.E.; Barry, P.J. Progress in definition, prevention and treatment of fungal infections in cystic fibrosis. Mycopathologia 2018, 183, 21-32. [CrossRef]

7. Sass, G.; Nazik, H.; Penner, J.; Shah, H.; Ansari, S.R.; Clemons, K.V.; Groleau, M.C.; Dietl, A.M.; Visca, P.; Haas, H.; et al. Studies of Pseudomonas aeruginosa mutants indicate pyoverdine as the central factor in inhibition of Aspergillus fumigatus biofilm. J. Bacteriol. 2017, 200, e00345-17. [CrossRef]

8. Nazik, H.; Sass, G.; Ansari, S.R.; Ertekin, R.; Haas, H.; Déziel, E.; Stevens, D.A. Novel intermicrobial molecular interaction: Pseudomonas aeruginosa quinolone signal (PQS) modulates Aspergillus fumigatus response to iron. Microbiology 2019, $166,44-55$. [CrossRef]

9. Sass, G.; Ansari, S.R.; Dietl, A.M.; Déziel, E.; Haas, H.; Stevens, D.A. Intermicrobial interaction: Aspergillus fumigatus siderophores protect against competition by Pseudomonas aeruginosa. PLoS ONE 2019, 14, e0216085. [CrossRef]

10. Chatterjee, P.; Sass, G.; Swietnicki, W.; Stevens, D.A. Review of potential Pseudomonas weaponry, relevant to the PseudomonasAspergillus interplay, for the Mycology community. J. Fungi 2020, 6, 81. [CrossRef]

11. Heymann, P.; Gerads, M.; Schaller, M.; Dromer, F.; Winkelmann, G.; Ernst, J. The siderophore iron transporter of Candida albicans (Sit1p/Arn1p) mediates uptake of ferrichrome-type siderophores and is required for epithelial invasion. Infect. Immun. 2002, 70, 5246-5255. [CrossRef]

12. Matthaiou, E.I.; Sass, G.; Stevens, D.A.; Hsu, J.L. Iron: An essential nutrient for Aspergillus fumigatus and a fulcrum for pathogenesis Curr. Opin. Infect. Dis. 2018, 31, 506-511. [CrossRef]

13. Reid, D.W.; Withers, N.J.; Francis, L.; Wilson, J.W.; Kotsimbos, T.C. Iron deficiency in cystic fibrosis: Relationship to lung disease severity and chronic Pseudomonas aeruginosa infection. Chest 2002, 121, 48-54. [CrossRef]

14. Reid, D.W.; Carroll, V.; O'May, C.; Champion, A.; Kirov, S.M. Increased airway iron as a potential factor in the persistence of Pseudomonas aeruginosa infection in cystic fibrosis. Eur. Respir. J. 2007, 30, 286-292. [CrossRef] [PubMed]

15. Pham, T.D.M.; Ziora, Z.M.; Blaskovich, M.A.T. Quinolone antibiotics. MedChemComm 2019, 10, 1719-1739. [CrossRef]

16. Bosso, J.A. Use of ciprofloxacin in cystic fibrosis patients. Am. J. Med. 1989, 87, 123S-127S. [CrossRef]

17. Scully, B.E.; Nakatomi, M.; Ores, C.; Davidson, S.; Neu, H.C. Ciprofloxacin therapy in cystic fibrosis. Am. J. Med. 1987, 82, 196-201.

18. Heeb, S.; Fletcher, M.P.; Chhabra, S.R.; Diggle, S.P.; Williams, P.; Cámara, M. Quinolones: From antibiotics to autoinducers. FEMS Microbiol. Rev. 2011, 35, 247-274. [CrossRef]

19. Ghelani, R. Ciprofloxacin (Ciproxin): An antibiotic for bacterial infections. Netdoctor. 2019. Available online: https://www. netdoctor.co.uk/medicines/infection/a28009/ciprofloxacin-uses-actions / (accessed on 9 December 2021).

20. Schrettl, M.; Bignell, E.; Kragl, C.; Joechl, C.; Rogers, T.; Arst, H.N., Jr.; Haynes, K.; Haas, H. Siderophore biosynthesis but not reductive iron assimilation is essential for Aspergillus fumigatus virulence. J. Exp. Med. 2004, 200, 1213-1219. [CrossRef]

21. Denning, D.W.; Clemons, K.V.; Hanson, L.H.; Stevens, D.A. Restriction endonuclease analysis of total cellular DNA of Aspergillus fumigatus isolates of geographically and epidemiologically diverse origin. J. Infect. Dis. 1990, 162, 1151-1158. [CrossRef]

22. Denning, D.W.; Stevens, D.A. Efficacy of cilofungin alone and in combination with amphotericin B in a murine model of disseminated aspergillosis. Antimicrob. Agents Chemother. 1991, 35, 1329-1333. [CrossRef]

23. Scudiero, D.A.; Shoemaker, R.H.; Paull, K.D.; Monks, A.; Tierney, S.; Nofziger, T.H.; Currens, M.J.; Seniff, D.; Boyd, M.R Evaluation of a soluble tetrazolium/formazan assay for cell growth and drug sensitivity in culture using human and other tumor cell lines. Cancer Res. 1988, 48, 4827-4833.

24. Sass, G.; Shrestha, P.; Stevens, D.A. Pseudomonas aeruginosa virulence factors support voriconazole effects on Aspergillus fumigatus. Pathogens 2021, 10, 519. [CrossRef]

25. Nazik, H.; Penner, J.C.; Ferreira, J.A.; Haagensen, J.A.; Cohen, K.; Spormann, A.M.; Martinez, M.; Chen, V.; Hsu, J.L.; Clemons, K.V.; et al. Effects of iron chelators on the formation and development of Aspergillus fumigatus biofilm. Antimicrob. Agents Chemother. 2015, 59, 6514-6520. [CrossRef] [PubMed]

26. Lee, K.; Yoon, S.S. Pseudomonas aeruginosa biofilm, a programmed bacterial life for fitness. J. Microbiol. Biotechnol. 2017, 27, 1053-1064. [CrossRef] [PubMed]

27. Kaur, S.; Singh, S. Biofilm formation by Aspergillus fumigatus. Med. Mycol. 2014, 52, 2-9. [CrossRef] [PubMed]

28. Naoi, T.; Shibuya, N.; Inoue, H.; Mita, S.; Kobayashi, S.; Watanabe, K.; Orino, K. The effect of tert-butylhydroquinone-induced oxidative stress in MDBK cells using XTT assay: Implication of tert-butylhydroquinone-induced NADPH generating enzymes. $J$. Vet. Med. Sci. 2009, 72, 321-326. [CrossRef] [PubMed]

29. McGaw, L.J.; Elgorashi, E.E.; Eloff, J.N. Cytotoxicity of African medicinal plants against normal animal and human cells. Toxicol. Surv. Afr. Med. Plants 2014, 181-233. [CrossRef]

30. Hangas, A.; Aasumets, K.; Kekäläinen, N.J.; Paloheinä, M.; Pohjoismäki, J.L.; Gerhold, J.M.; Goffart, S. Ciprofloxacin impairs mitochondrial DNA replication initiation through inhibition of Topoisomerase 2. Nucleic Acids Res. 2018, 46, 9625-9636. [CrossRef]

31. LeBel, M. Ciprofloxacin: Chemistry, mechanism of action, resistance, antimicrobial spectrum, pharmacokinetics, clinical trials, and adverse reactions. Pharmacotherapy 1988, 8, 3-33. [CrossRef]

32. Stergiopoulou, T.; Meletiadis, J.; Sein, T.; Papaioannidou, P.; Tsiouris, I.; Roilides, E.; Walsh, T.J. Isobolographic analysis of pharmacodynamic interactions between antifungal agents and ciprofloxacin against Candida albicans and Aspergillus fumigatus. Antimicrob. Agents Chemother. 2008, 52, 2196-2204. [CrossRef] 
33. Brilhante, R.S.; Caetano, E.P.; Sidrim, J.J.; Cordeiro, R.A.; Camargo, Z.P.; Fechine, M.A.; Lima, R.A.; Castelo Branco, D.S.; Marques, F.J.; Mesquita, J.R.; et al. Ciprofloxacin shows synergism with classical antifungals against Histoplasma capsulatum var. capsulatum and Coccidioides posadasii. Mycoses 2012, 56, 397-401. [CrossRef]

34. Ben Yaakov, D.; Shadkchan, Y.; Albert, N.; Kontoyiannis, D.P.; Osherov, N. The quinolone bromoquinol exhibits broadspectrum antifungal activity and induces oxidative stress and apoptosis in Aspergillus fumigatus. J. Antimicrob. Chemother. 2017, 72, 2263-2272. [CrossRef]

35. D’Espine, M.; Bellido, F.; Pechère, J.C.; Auckenthaler, R.; Rohner, P.; Lew, D.; Hirschel, B. Serum levels of ciprofloxacin after single oral doses in patients with septicemia. Eur. J. Clin. Microbiol. Infect. Dis. 1989, 8, 1019-1023. [CrossRef]

36. Kontou, P.; Chatzika, K.; Pitsiou, G.; Stanopoulos, I.; Argyropoulou-Pataka, P.; Kioumis, I. Pharmacokinetics of ciprofloxacin and its penetration into bronchial secretions of mechanically ventilated patients with chronic obstructive pulmonary disease. Antimicrob. Agents Chemother. 2011, 55, 4149-4153. [CrossRef]

37. Lim, J.U.; Hong, S.W.; Ko, J.H. Efficacy of inhaled ciprofloxacin agents for the treatment of bronchiectasis: A systematic review and meta-analysis of randomized controlled trials. Ther. Adv. Respir. Dis. 2019, 13, 1753466619875930. [CrossRef]

38. Dalhoff, A. Pharmacokinetics and pharmacodynamics of aerosolized antibacterial agents in chronically infected cystic fibrosis patients. Clin. Microbiol. Rev. 2014, 27, 753-782. [CrossRef]

39. Polk, R.E.; Healy, D.P.; Sahai, J.; Drwal, L.; Racht, E. Effect of ferrous sulfate and multivitamins with zinc on absorption of ciprofloxacin in normal volunteers. Antimicrob. Agents Chemother. 1989, 33, 1841-1844. [CrossRef]

40. Andriole, V.T. The quinolones history and overview. In The Quinolones; Academic Press: San Diego, CA, USA, $2000 ;$ p. 22.

41. Kara, M.; Hasinoff, B.B.; McKay, D.W.; Campbell, N.R. Clinical and chemical interactions between iron preparations and ciprofloxacin. Br. J. Clin. Pharmacol. 1991, 31, 257-261. [CrossRef]

42. Wang, J.; Lory, S.; Ramphal, R.; Jin, S. Isolation and characterization of Pseudomonas aeruginosa genes inducible by respiratory mucus derived from cystic fibrosis patients. Mol. Microbiol. 1996, 22, 1005-1012. [CrossRef] 